\title{
Phase Field Simulation of Equiaxed Microstructure Formation during Semi-solid Processing of A380 Al Alloy
}

\author{
Prosenjit DAS, ${ }^{1,2)}$ Sudip Kumar SAMANTA, ${ }^{1)}$ Pramod KUMAR ${ }^{2)}$ and Pradip DUTTA ${ }^{2 / *}$ \\ 1) NNMT Group, CSIR-Central Mechanical Engg. Research Institute, Durgapur-713209 India. \\ 2) Department of Mechanical Engineering, Indian Institute of Science, Bangalore-560012 India.
}

(Received on September 18, 2013; accepted on March 17, 2014)

\begin{abstract}
A phase field modelling approach is implemented in the present study towards simulation of microstructure evolution during cooling slope semi solid slurry generation process of A380 Aluminium alloy. First, experiments are performed to evaluate the number of seeds required within the simulation domain to simulate near spherical microstructure formation, occurs during cooling slope processing of the melt. Subsequently, microstructure evolution is studied employing a phase field method. Simulations are performed to understand the effect of cooling rate on the slurry microstructure. Encouraging results are obtained from the simulation studies which are validated by experimental observations. The results obtained from mesoscopic phase field simulations are grain size, grain density, degree of sphericity of the evolving primary Al phase and the amount of solid fraction present within the slurry at different time frames. Effect of grain refinement also has been studied with an aim of improving the slurry microstructure further. Insight into the process has been obtained from the numerical findings, which are found to be useful for process control.
\end{abstract}

KEY WORDS: semisolid; cooling slope; phase field; primary Al; spheroids; equiaxed.

\section{Introduction}

Microstructure of polycrystalline materials serves as the strategic link between material processing history and its properties, hence it is referred usually as the heart of material science and engineering. ${ }^{1)}$ Microstructure arises in case of a polycrystalline material due to compositional and structural in homogeneities occurring during processing of materials. ${ }^{2)}$ To establish control over microstructure formation during materials processing, quantative computation of microstructural features has become inevitable now-a-days. Phase field approach has emerged as a powerful technique for computation of nonlinear nature of microstructure evolution during solidification and solid state transformations. ${ }^{3)}$ Though the method has been developed keeping in view of simulating solidification microstructures ${ }^{4}$ but it has been applied in several different fields over the past few decades. ${ }^{5,6)}$ In case of phase field modelling of solidification, field variables are introduced purposefully to avoid solid/liquid interface tracking.

Phase field technique enables simulation of microstructural features at mesoscale and allows input of material specific properties, usually determined from theoretical investigations or experimental findings. Phase field technique facilitates consideration of different driving forces such as reduction in interfacial energy, bulk free energy and elastic strain energy for microstructure evolution simulations. The merit behind popularization of this method lies in its nature of diffuse-interface description. A phase-field variable $\phi$ is employed in this technique as a function of position and time to differentiate between liquid and solid phases. The variable has fixed values for both the solid and liquid phases

* Corresponding author: E-mail: pradip@mecheng.iisc.ernet.in DOI: http://dx.doi.org/10.2355/isijinternational.54.1601
( 1 and 0 , respectively), which undergoes smooth change in the interface. ${ }^{7,8)}$ Thus, the phase field method enables simulation of microstructure evolution in alloys having complicated grain morphology without initial assumption of grain shapes. Phase field equations are coupled with the equations for heat and solute transport to avoid complexity of giving boundary conditions at the solid/liquid interface. The technique also treats topology changes of two adjacent solid grains, present at close proximity, at ease. The present study discusses application of phase field modelling technique to simulate microstructure evolution during semisolid processing of $\mathrm{Al}-\mathrm{Si}-\mathrm{Mg}-\mathrm{Cu}$ (A380) alloy. A brief description of semisolid manufacturing (SSM) technology is given below.

Efforts of continuous improvement in cast component's mechanical properties and structural integrity sets the stage for Semisolid metal processing (SSM) technology in today's manufacturing industry. The reason behind popularization of SSM lies in its capability of combining the benefits attained by two classical forming processes i.e., casting and forging together.9,10) Specially prepared semi-solid slurry having near spherical primary solid particles plays a pivotal role towards the success story of SSM. ${ }^{11-13)}$ There are several variants of semisolid forming processes, reported in archived literature such as thixocasting, rheocasting, rheomoulding, and thixomoulding. All the above methods require prior semisolid slurry preparation. Several researchers worldwide have worked on different slurry generation techniques such as electromagnetic stirring, stress-induced and melt-activated (SIMA) process, Magneto Hydrodynamic Stirring (MHD), cooling slope, vibration, and so on. ${ }^{11-15}$ )

$\mathrm{A} 380$ is a $\mathrm{Al}-\mathrm{Si}-\mathrm{Mg}-\mathrm{Cu}$ alloy which is used potentially for die casting applications. Several different components of automotive industry such as brake drum, brackets, manifolds, valve bodies, air cooled cylindrical heads and gear cases are being manufactured using this alloy at present. ${ }^{16)}$ 
The advantages offered by A380 include fluidity, castability, resistance towards hot cracking and good mechanical properties. This is due to the fact that this alloy combines the advantages of $\mathrm{Al}-\mathrm{Si}$ and $\mathrm{Al}-\mathrm{Cu}$ alloy systems. ${ }^{17)}$ The presence of silicon increases fluidity and castability, and copper provides higher strength than the straight Al-Si alloys. ${ }^{18,19)}$ Literature available on semi-solid processing of A380 Al alloy is scarce and generally experimental in nature. ${ }^{16,20,21)}$

In view of the above the present work has been taken up and a cooling slope is employed to prepare semi-solid slurry of A380 Al alloy. The cooling slope slurry generation technique is found simple and cost effective one in terms of possible industrial implementation by many researchers across the globe and a brief literature review is presented in our earlier published work. ${ }^{22-24)}$ Present study is focused towards the investigation of physics associated with microstructure evolution during cooling slope semi-solid slurry generation of $\mathrm{A} 380 \mathrm{Al}$ alloy by the application of Phase field simulation technique and subsequent experimental validation. The results obtained are novel as per author's knowledge of the existing literature.

Cooling slope slurry generation has been performed by allowing the superheated molten alloy having $903 \mathrm{~K}$ pouring temperature ${ }^{16)}$ to flow along the slope made of stainless steel. Solid nucleation occurs at the melt contact zone with the slope due to rapid heat transfer. Nucleated particles are detached and carried forward by the flowing melt. Nucleation and growth mechanism of primary $\mathrm{Al}$ grains and shear driven melt flow along the slope transforms the alloy melt into semi-solid slurry with near spherical primary phase morphology up to the slope exit. To enhance the degree of sphericity and to decrease primary particle size within the slurry, effect of grain refiner addition into the melt is studied in this work. Microstructure evolution during this process is simulated using phase field method, with the help of commercially available solver Micress. ${ }^{25-31)}$ Thermodynamic descriptions needed to simulate microstructure evolution are provided by coupling CALPHAD with Micress software. The simulation results are then compared with the experimental observations.

\section{Description of the Phase Field Model}

The phase field model used here describes the evolution of multiple phase-field parameters $\phi_{\alpha}(x, t)$ in time and space. The field variable maps the spatial distribution of grains having different orientations and also different phases having distinct thermodynamic properties. Phase field variable of a particular phase $\alpha$ assumes a value of $0\left(\phi_{\alpha}=0\right)$ if the phase is not present locally, and it assumes a value of $1\left(\phi_{\alpha}=\right.$ 1 ) if the phase $\alpha$ is present. Diffuse-interface description of the model is implemented by having the field variables change continuously from 0 to 1 over an interface thickness $\eta$. The interface thickness $\eta$ is large compared to that of the atomic interface thickness whereas it is small in comparison to the microstructural length scale. Free energy formulation for the time evolution of different phases is summarized below. A detailed description of the phase field model is found elsewhere. ${ }^{31-35)}$

$$
\begin{aligned}
& F=\int_{\Omega} f^{I F}+\int f^{C H} \\
& \left.f^{I F}=\sum_{\alpha, \beta=1}^{N} \frac{4 \sigma_{\alpha \beta}}{\eta_{\alpha \beta}}\left(\frac{\left(\eta_{\alpha \beta}\right)^{2}}{\pi^{2}}\left|\nabla \phi_{\alpha} \cdot \nabla \phi_{\beta}\right|+W_{\alpha \beta}\right)\right) \ldots \ldots . \\
& f^{C H}=\sum_{\alpha=1}^{N} \phi_{\alpha} f_{\alpha}\left(\overrightarrow{c_{\alpha}}\right)+\vec{\mu}\left(\vec{c}-\sum_{\alpha=1}^{N} \phi_{\alpha} \overrightarrow{c_{\alpha}}\right)
\end{aligned}
$$

$$
\begin{aligned}
& \dot{\phi}_{\alpha}=\sum_{\beta} M_{\alpha \beta}(\vec{n})\left(\sigma_{\alpha \beta}(\vec{n}) K_{\alpha \beta}+\frac{\pi}{\eta} \sqrt{\phi_{\alpha} \phi_{\beta}} \Delta G_{\alpha \beta}(\vec{c}, T)\right) \\
& K_{\alpha \beta}=\phi_{\beta} \nabla^{2} \phi_{\alpha}-\phi_{\alpha} \nabla^{2} \phi_{\beta}+\left(\frac{\pi}{\eta}\right)^{2}\left(\phi_{\alpha}-\phi_{\beta}\right) \\
& \Delta G_{\alpha \beta}=-f_{\alpha}\left(\overrightarrow{c_{\alpha}}\right)+f_{\beta}\left(\overrightarrow{c_{\beta}}\right)+\vec{\mu}\left(\overrightarrow{c_{\alpha}}-\overrightarrow{c_{\beta}}\right) \\
& \dot{\vec{c}}=v^{m} \nabla \sum_{\alpha=1}^{N} \phi_{\alpha} M_{\alpha}^{c h}\left(\overrightarrow{c_{\alpha}}\right) \nabla \mu_{\alpha} \text { with } \sum_{\alpha=1}^{N} \phi_{\alpha} M_{\alpha}^{c h}=M^{c h} \ldots \\
& \dot{\vec{c}}=\nabla \sum_{\alpha=1}^{N} \phi_{\alpha} \vec{D}_{\alpha} \nabla \overrightarrow{c_{\alpha}} \text { with } D_{\alpha}=v^{m} M_{\alpha}^{c h} T_{\alpha} \text { and } T_{\alpha}^{i j}=\frac{\partial \mu_{\alpha}^{i}}{\partial c_{\alpha}^{j}} \\
& D_{\alpha}^{(0) i j}=D_{\alpha}^{i j}-D_{\alpha}^{j 0}
\end{aligned}
$$

In Eq. (1), $f^{I F}$ is the interfacial part of the free energy and $f^{C H}$ is the chemical part. In Eq. (2), $f^{I F}$ is composed of grain boundary energy $\sigma_{\alpha \beta}$ between phases $\alpha$ and $\beta$ and grain boundary width $\eta_{\alpha \beta}$. Double obstacle potential is $W_{\alpha \beta}$ between $\alpha$ and $\beta$ phase. In Eq. (3), $f^{C H}$ is a linear mixture of bulk contributions of individual phases where $\mu$ is the generalized chemical potential to conserve the local concentration. In Eq. (4), $M_{\alpha \beta}$ is the mobility of the interface as a function of the interface orientation, described by the normal vector $\vec{n} . \sigma_{\alpha \beta}$ is the effective anisotropic surface energy (surface stiffness), and $K_{\alpha \beta}$ (Eq. (5)) is related to the local curvature of the interface. The interface, on the one hand, is driven by the curvature contribution $\sigma_{\alpha \beta} K_{\alpha \beta}$, and on the other hand, by the thermodynamic driving force $\Delta G_{\alpha \beta}$ (Eq. (6)).

In Eq. (7) of the present phase field model $\vec{c}$ is the local (multicomponent) composition, $M_{\alpha}^{c h}$ is the chemical motility of individual phases, $v^{m}$ is the mean molar volume and $\mu_{\alpha}$ is the diffusion potential of individual phases. To obtain numerical solution of diffusion equations, the gradient of diffusion potentials in the present model are replaced by the gradient of compositions (mole fraction), and the resulting expression is shown in Eq. (8), where the matrix $T$ comprises of the derivatives of diffusion potentials with respect to the composition of different phases. The thermodynamic driving force, which is a function of temperature $T$ and local (multicomponent) composition $\vec{c}$ (Eq. (8)), couples the phase-field equations to the diffusion equations. $\vec{D}_{\alpha}$, the multicomponent diffusion coefficient matrix for phase $\alpha$, is calculated in the present work from databases (Moball) for the given concentration and temperature. Multiplication of the chemical mobility matrix $M$ and the matrix $T$ gives the diffusion matrix D. In case of substitutional system, reduced diffusion matrix is given in Eq. (9). Detailed description on diffusion equations considered in the present phase field model may be seen elsewhere. ${ }^{36)}$

The abovementioned model is implemented in MICRESS software, which has been used for the present simulations.

\section{Experimental Procedure}

A380 Al alloy (composition shown in Table 1) is used for the present experiments. A cooling slope made of stainless steel is used to prepare semi-solid slurry of the said alloy. Schematic diagram of the experimental facility is shown in Fig. 1. The as-received A380 ingot is melted in a resistance heating furnace of $5 \mathrm{~kg}$ melt capacity. The furnace is set at $1023 \mathrm{~K}$ for melting. For performing the experiments, $2 \mathrm{~kg}$ of A380 alloy is melted in a silicon carbide crucible located 
within the resistance furnace. The melt is then degassed and allowed to cool down to the desired pouring temperature of $903 \mathrm{~K}^{16)}$ to pour into the cooling slope having $60^{\circ} \mathrm{C}$ wall temperature, placed at $60^{\circ}$ slope angle with respect to the horizontal plane and allowed to flow along $500 \mathrm{~mm}$ slope length. Previous experience with A356 Al alloy has been utilized to select the processing parameters, used in this study. $^{22-24)}$ Liquidus, solidus and eutectic temperatures of the alloy are $855 \mathrm{~K}, 797 \mathrm{~K}$ and $841 \mathrm{~K}$, respectively. ${ }^{16)}$ Smoother melt flow (without sticking to the slope surface) along the slope during the experiments is ensured by applying boron nitride on the slope surface. K-type thermocouples are placed at three different locations of the slope to track the melt temperatures, which are recorded using rapid data acquisition software (Scada). ${ }^{37)}$

A silicon carbide crucible having $10 \mathrm{~mm}$ hole at the bottom is used for bottom pouring the molten alloy into the slope at a controlled rate. For some cases, grain refiner (Al$5 \mathrm{Ti}-1 \mathrm{~B}, 0.15 \%$ by weight) is added before allowing the melt to flow along the slope. Successive melt samples, collected from the top, middle and exit section of the melt flow, are collected during melt flow along the slope and quenched in the oil to study the microstructure evolution mechanism of primary Al phase. The experiment performed in case of unrefined and grain refined alloy is repeated thrice to ensure repeatability. Detailed description of experimental set-up and experimental procedure may be seen from our earlier published literature. ${ }^{38-40)}$

In the present study, grain Diameter (GD) and sphericity of the primary $\mathrm{Al}$ particles are calculated using image analysis software Image J. The equations used to evaluate grain size and sphericity are written below. ${ }^{38-40)}$

$$
\begin{gathered}
G . D=2 \sqrt{A_{\alpha} / \pi} \\
S . F=\left(4 \pi A_{\alpha} / P_{\alpha}^{2}\right)
\end{gathered}
$$

Where, $A \alpha$ and $P \alpha$ denote the area and perimeter of primary $\alpha$-Al phase, respectively. It may be noted here that each globule is treated as a separate grain. In this context, it should be mentioned that the shape factor close to 1 is desirable for optimum semi-solid processing.

Table 1. Showing chemical composition of A380 Aluminium alloy used in the experiment.

\begin{tabular}{ccccccccccc}
\hline $\mathrm{Si}$ & $\mathrm{Mg}$ & $\mathrm{Mn}$ & $\mathrm{Cu}$ & $\mathrm{Fe}$ & $\mathrm{Ti}$ & $\mathrm{Ni}$ & $\mathrm{Cr}$ & $\mathrm{Zn}$ & $\mathrm{Pb}$ & $\mathrm{Al}$ \\
\hline 8.51 & 0.025 & 0.189 & 3.56 & 0.91 & 0.037 & 0.062 & 0.045 & 1.65 & 0.069 & 84.9 \\
\hline
\end{tabular}

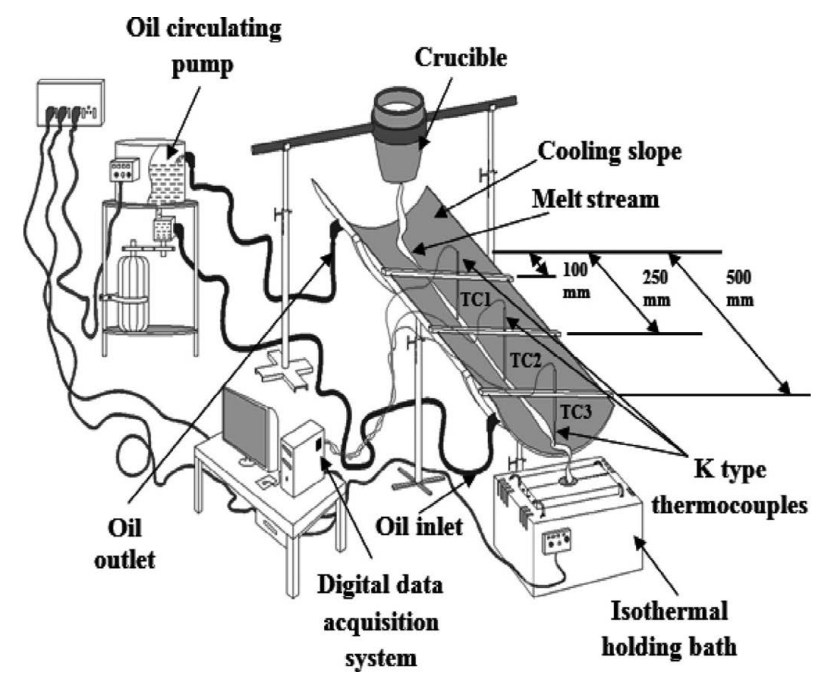

Fig. 1. Schematic diagram of the Experimental facility.

\section{Simulation Methodology}

In this study phase field simulations are performed using Micress considering a $300 \mu \mathrm{m} \times 300 \mu \mathrm{m}$ calculation domain with $2 \mu \mathrm{m}$ grid spacing. Thermodynamic data such as composition, temperature and pressure dependence of the Gibbs energies are taken from TCAL1 and mobility data are taken from Moball database of Thermo Scientific. Coupling of the thermodynamic database with the present simulations are performed using TQ interface of Micress. Details on thermodynamic coupling may be seen elsewhere. ${ }^{33-35)} \mathrm{Al}-$ $\mathrm{Si}-\mathrm{Mg}-\mathrm{Cu}$ (A380) alloy is considered for the present calculations. The composition is same as that shown in Table 1, with all elements having less than $0.2 \mathrm{wt} \%$ being omitted. In this context, it should be mentioned that the simulation terminates in semi-solid condition; hence nucleation of primary Al phase only is considered within the bulk liquid. Cross-diffusion effects and convection are neglected in the present simulations. Heterogeneous nucleation is considered to replicate the crystal separation mechanism ${ }^{38,39)}$ occurring during semi-solid slurry generation using cooling slope. Seed density model of nucleation is considered for heterogeneous nucleation in the present simulations.

Interfacial properties are defined as 'anisotropic', i.e., as function of the interface normal vector $\vec{n}=\left(n_{x}, n_{y}, n_{z}\right)$ transformed into the coordinate system of the anisotropic grain. In the present work, anisotropic functions used for the FCC (face centered cubic) primary $\mathrm{Al}$ crystals are shown below:

$$
\text { Static : } a_{\sigma^{*}}=1-\delta_{\sigma^{*}} 4\left(n_{x}^{4}+n_{y}^{4}+n_{z}^{4}\right)
$$

For $2 \mathrm{D}$ (in the present case) : $a_{\sigma}=1-\delta_{\sigma} \cos 4 \phi$

$$
\text { Kinematic: } a_{\mu}=1-\delta_{\mu} 4\left(n_{x}{ }^{4}+n_{y}{ }^{4}+n_{z}{ }^{4}\right)
$$

For 2D (in the present case) : $a_{\mu}=1+\delta_{\mu} \cos 4 \phi$

Where, $\delta_{\sigma^{*}}, \delta_{\mu}$ are the static and kinematic anisotropy coefficients, $\phi$ is the Euler angle of grain orientation and $\sigma^{*}$ is the liquid/solid interfacial stiffness. In this context, interfacial stiffness is related to the liquid/solid interfacial energy as follows:

$$
\sigma^{*}=\sigma+\frac{d^{2} \sigma}{d \phi^{2}}
$$

Detailed description about anisotropic model may be seen from these literatures. ${ }^{33,34,40)}$ Static and kinematic anisotropy coefficients, values of surface energy and interface mobility used in the present phase field calculation are shown in Table 2.

\subsection{Nucleation Model}

In the present study heterogeneous nucleation of primary Al particles has been considered for microstructure formation. To avoid continuous growth, as happens in case of directional solidification, some seed particles are added to suppress columnar growth. These seed particles mark the starting points for nucleation for a given undercooling:

Table 2. Numerical parameters and physical constants.

\begin{tabular}{ccccccc}
\hline $\begin{array}{c}\text { Static } \\
\text { anisotropy } \\
\text { coefficient }\end{array}$ & $\begin{array}{c}\text { Kinematic } \\
\text { anisotropy } \\
\text { coefficient }\end{array}$ & $\begin{array}{c}\text { Liquid/solid } \\
\text { surface } \\
\text { energy } \\
\left(\mathrm{J} / \mathrm{cm}^{2}\right)\end{array}$ & $\begin{array}{c}\text { Kinetic } \\
\text { coefficient } \\
\text { between } \\
\text { phases } \\
\left(\mathrm{cm}^{4} / \mathrm{Js}\right)\end{array}$ & $\begin{array}{c}\text { Liquidus } \\
\text { temp. }\end{array}$ & $\begin{array}{c}\text { Solidus } \\
\text { temp. }\end{array}$ & $\begin{array}{c}\text { Eutectic } \\
\text { t(K) }\end{array}$ \\
\hline 0.5 & 0.2 & $2.0 \mathrm{E}-05$ & $5.0 \mathrm{E}-02$ & 855 & 797 & 841 \\
\hline
\end{tabular}




$$
\Delta T_{N u c}=\frac{4 \gamma}{\Delta S d}
$$

Where, $\Delta S$ is the entropy of fusion, $d$ is the grain diameter of primary $\mathrm{Al}$ particles and $\gamma$ is the liquid/solid interfacial energy. In this context it should be mentioned that the entropy of fusion between liquid and solid primary Al particles is obtained from thermodynamic databases used in the present study. The size distribution of seed particles is shown in Fig. 2 and liquid/solid interfacial energy is assumed as $1.00000 \mathrm{E}-05 \mathrm{~J} / \mathrm{cm}^{2}$

The effectiveness of seed particles towards microstructure formation is defined by their maximum particle size and size distribution. During heat extraction from the melt biggest particles nucleate first at an undercooling defined by their radii. Subsequently, the nucleated particles grow and release latent heat. During growth, nucleated particles interact with other seeds. Hence, depending on the heat extraction rate, number, and size distribution of other seed particles, the melt temperature drops below the liquidus temperature and defines the number of activated seeds. Seed distribution assumed for the present simulations is shown in Fig. 2. Based on the earlier published literature and numerical experiments, 25 different seed sizes having different density are chosen to simulate near spherical microstructural features occurs in case of cooling slope rheocasting process. Detailed description on the present nucleation model implemented in Micress may be seen from these articles. ${ }^{33,34,41)}$

One hundred and fifty seeds are placed randomly within the bulk liquid i.e., within the simulation domain in case of

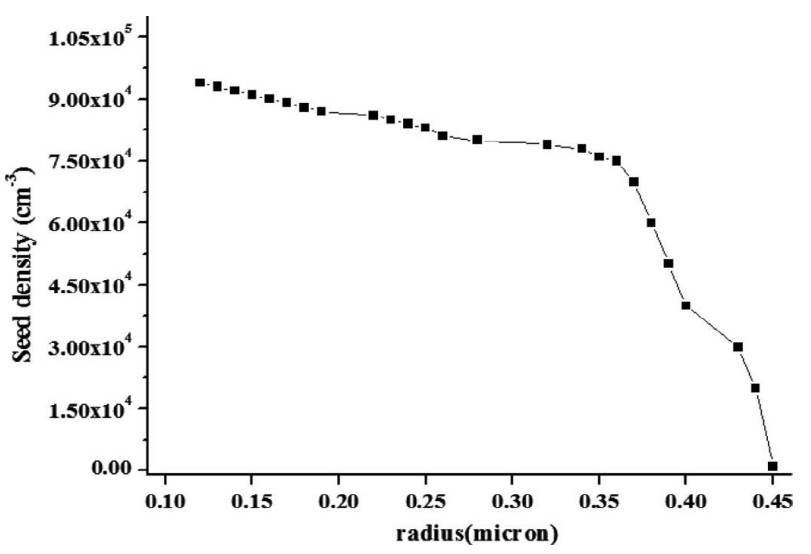

Fig. 2. Assumed radius distribution of the seed particles.

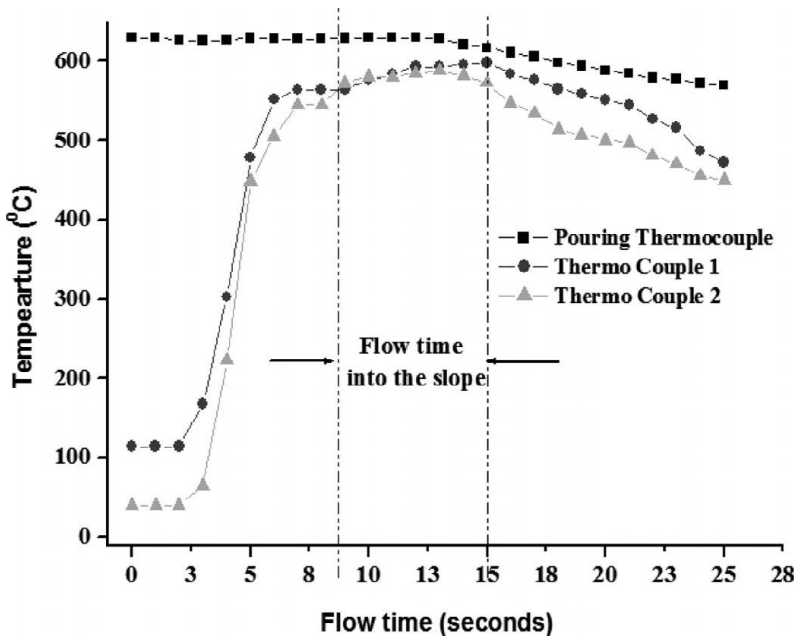

Fig. 3. Temperature vs. flow time plot for the unrefined alloy. unrefined melt, and 200 seeds in case of grain refined melt of A380 Al alloy. The number of seeds required for simulation is approximated from the experimental micrograph obtained from oil quenched slurry samples, collected just after the melt comes in contact with the slope. The number of particles present within the experimental micrograph of refined and unrefined samples is counted, from which the number of seeds for the $300 \mu \mathrm{m} \times 300 \mu \mathrm{m}$ simulation domain is approximated by linear interpolation. The cooling rate is estimated experimentally from the temperature history, obtained using $\mathrm{K}$ type thermocouples placed sequentially along the cooling slope. Figure 3 shows the temperature vs. flow time plot wherefrom the cooling rate is estimated in case of unrefined melt by dividing the total temperature drop $(57 \mathrm{~K})$ by cooling time (6 seconds). Effect of cooling rate on microstructure evolution is studied in case of unrefined melt, keeping all other conditions fixed. Latent heat release is distributed equally over the entire simulation domain, as described in. ${ }^{28,34)}$

\section{Results and Discussions}

\subsection{Simulation Results}

The calculation starts with a homogenous melt kept at 903 K. Firstly, the nucleants distribution function is read into the phase field solver and accordingly, nucleants having different radii are positioned within the bulk melt of A380 Al alloy. During simulation a new embryo forms within the melt only if the local undercooling, which is a function of local melt composition and temperature, becomes more than that of critical undercooling. In this context, it should be mentioned that the required critical undercooling is evaluated as a function of radius of the seed particles. Depending on the local thermodynamic condition prevailing within the melt, the embryo either grows or shrinks. When a nucleant
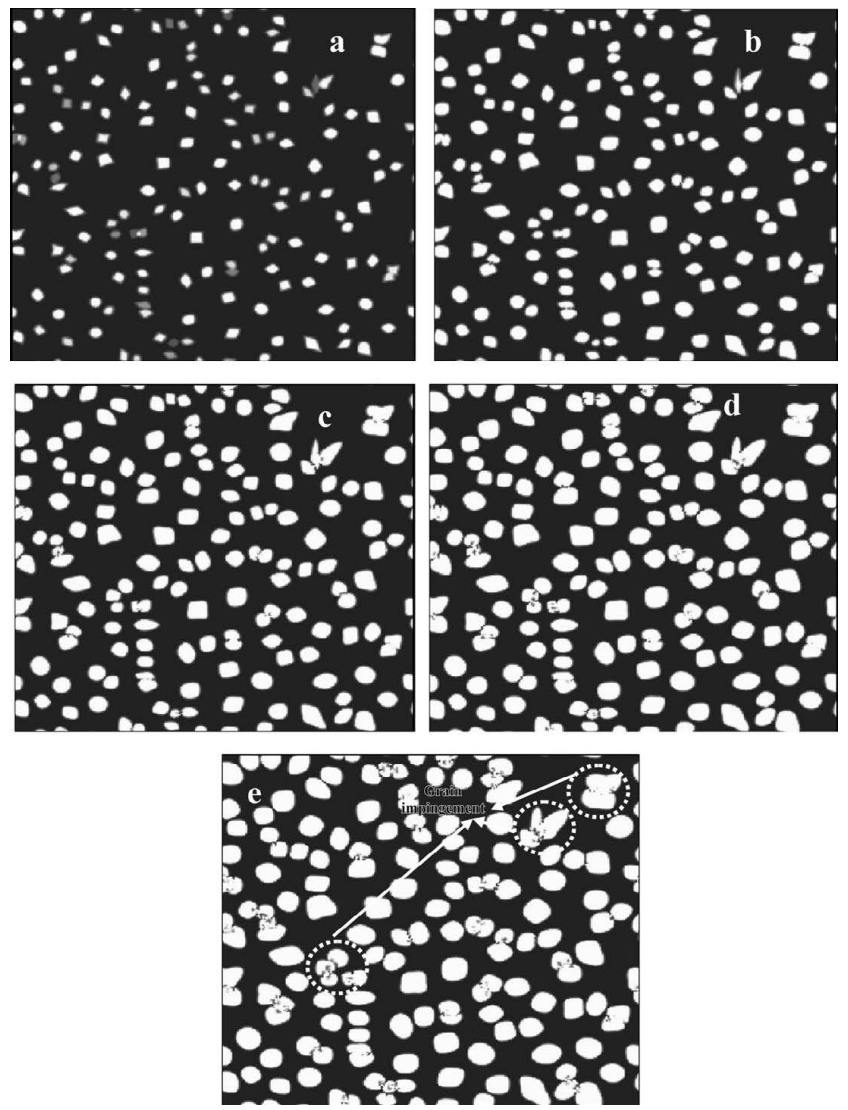

Fig. 4. Simulated micrographs of the unrefined melt (cooling rate $9.5 \mathrm{~K} / \mathrm{s}$ ) after (a) 2, (b) 3 , (c) 4 , (d) 5 and (e) 6 seconds. 
grows, it redistributes solute and releases latent heat to facilitate further nucleation.

It is estimated from experimentation that the melt takes about 6 seconds to flow down the slope after pouring into the cooling slope. In line with that the simulation runs are performed for 6 seconds in this study. Figure 4 shows the simulated micrographs pertaining to the unrefined melt (cooling rate $9.5 \mathrm{~K} / \mathrm{s}$ ) after $2,3,4,5$ and 6 seconds. After 2 seconds, burst nucleation of primary $\mathrm{Al}$ phase is observed within the bulk liquid (simulation domain). Subsequent growth of the nucleated primary particles may be seen from the simulated micrographs of 3, 4, 5 and 6 seconds. Though most of the particles, originating from heterogeneous nucleation, are found to be isolated, presence of grain impingement and cluster formation due to agglomeration is observed in some locations. Hence, chances of particle sintering, coalescence and coagulation can be predicted in this case. In practical cases, coalescence or sintering initiates from grain impingement and becomes active based on the local thermo-solutal condition prevails within the melt, as also evidenced from the experimental findings shown subsequently. Noticeable presence of grain impingement and agglomeration is observed within the simulation domain after 6 seconds, which signifies that further cooling of the semi-solid slurry will result in decreased sphericity of the primary particles. Quantative results of grain growth, grain density, solid fraction evolution and sphericity of the primary particles at different simulation times are shown and discussed subsequently in the manuscript.

Effect of cooling rate on microstructure evolution is studied by using two cooling rates: $8.3 \mathrm{~K} / \mathrm{s}$ and $11 \mathrm{~K} / \mathrm{s}$. At the lower cooling rate of $8.3 \mathrm{~K} / \mathrm{s}$ (Fig. 5), a smaller number of seeds become active. Fewer nucleated particles result in decrease of solid fraction and grain density, whereas higher grain size is observed in this case due to preferential growth of the primary particles during slow cooling. Ripening driven growth in this case decreases the degree of sphericity of the microstructure.

Increasing the cooling rate affects the microstructural morphology in a negative manner, as it reduces sphericity of the primary aluminum grains. Though higher cooling rate $(11 \mathrm{~K} / \mathrm{s})$ yields higher solid fraction in the melt, it enhances the chances of coalescence, sintering of primary particles and hence decreases their degree of sphericity (Fig. 6). It is not found to be favorable for cooling slope slurry formation as the generated primary aluminum particles within the melt shows high curvature and edgy appearance, which creates opportunity for growth of primary particles in dendritic manner. As isolated particles have been considered as individual grains, grain size is found higher compared to that of $9.5 \mathrm{~K} / \mathrm{s}$ cooling rate. Quantative results are shown subsequently.

Grain refiner addition into the melt is simulated by increasing the seed density within the bulk melt and the simulated micrographs for different simulation time are shown in Fig. 7. Simulated micrographs show clear improvement in terms of lower grain size and higher sphericity of the primary particles. Though solid fraction is higher in this case compared to that of unrefined melt, higher seed density ensures spheroidal growth. Hence, chances of coagulation and particle sintering are less in this case, which confirms the effectiveness of controlled inoculation during cooling slope semi-solid slurry generation of the alloy melt under investigation.

Quantitative findings from the simulation study are presented in Figs. 8, 9, 10 and 11. Figure 8 shows the grain density present within the simulation domain at various simulation times for different simulation conditions. Error bars $( \pm 3 \%)$ are given to counter the effect of variability in simulation results. Lowest grain density is observed in case of
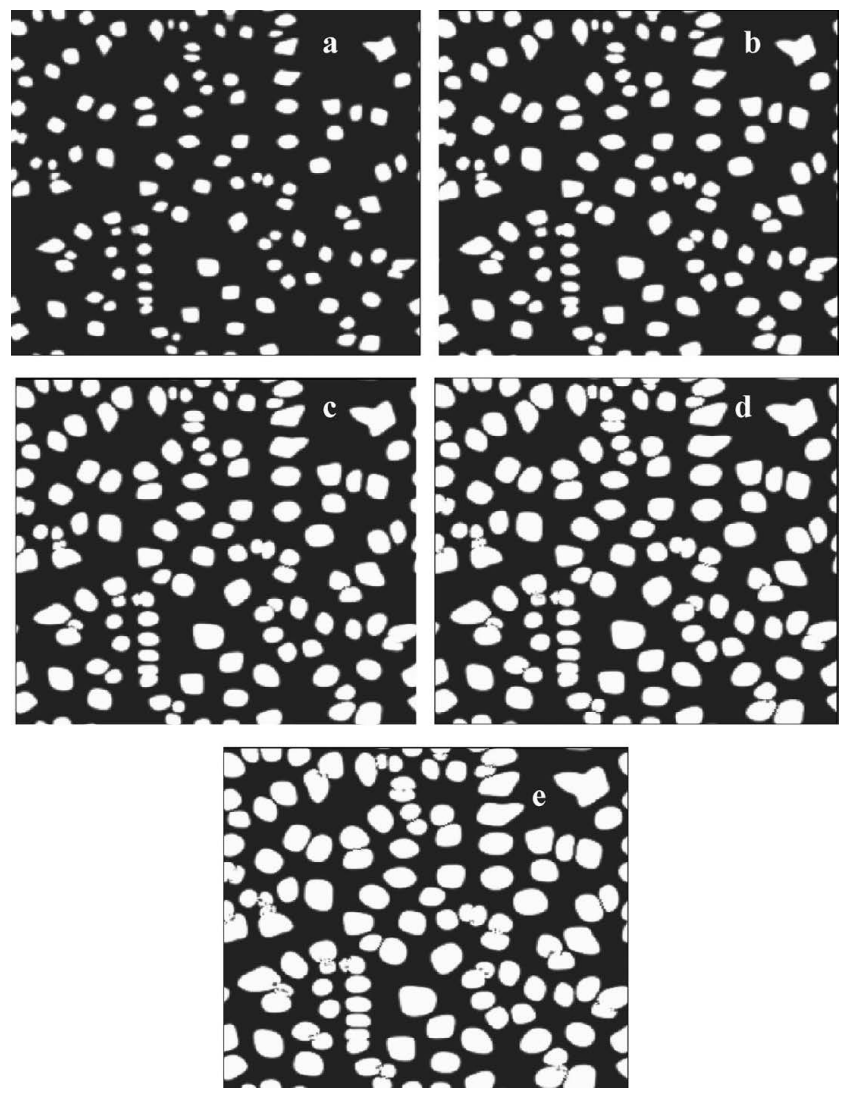

Fig. 5. Simulated micrographs of the unrefined melt (cooling rate $8.3 \mathrm{~K} / \mathrm{s}$ ) after (a) 2, (b) 3, (c) 4, (d) 5 and (e) 6 seconds.
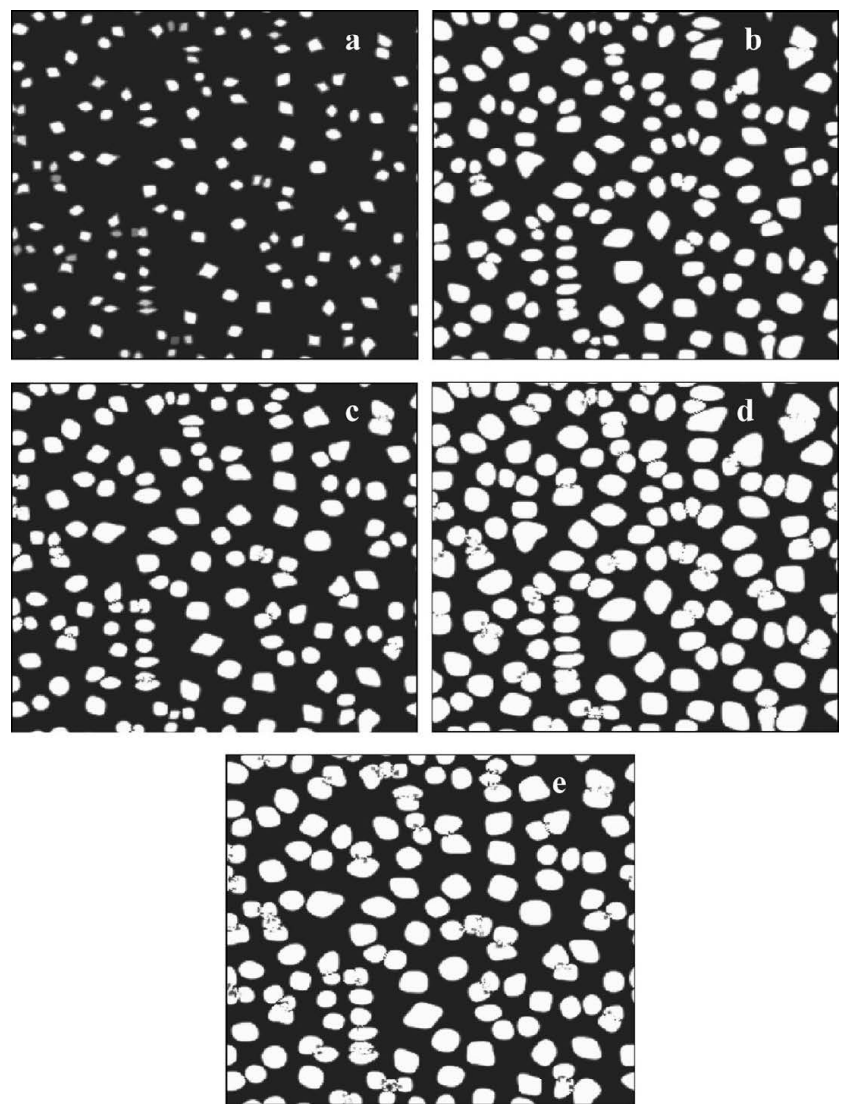

Fig. 6. Simulated micrographs of the unrefined melt (cooling rate $11 \mathrm{~K} / \mathrm{s}$ ) after (a) 2, (b) 3, (c) 4, (d) 5 and (e) 6 seconds. 
$8.3 \mathrm{~K} / \mathrm{s}$ cooling rate during the whole timeframe of microstructure evolution due to less undercooling. In case of cooling rate of $11 \mathrm{~K} / \mathrm{s}$, grain density is found to be higher up to 5 seconds of simulation time, but subsequent dominance of particle coarsening mechanisms brings down the effective number of grains present within the simulation domain. A maximum grain density of $4.55 \mathrm{E}-4 / \mu \mathrm{m}^{2}$ is obtained in case of grain refined melt after 6 seconds of simulation time, which confirms significant improvement attained by grain refinement. Solid fraction evolved within the bulk liquid for all simulation conditions is shown in Fig. 9. Presence of
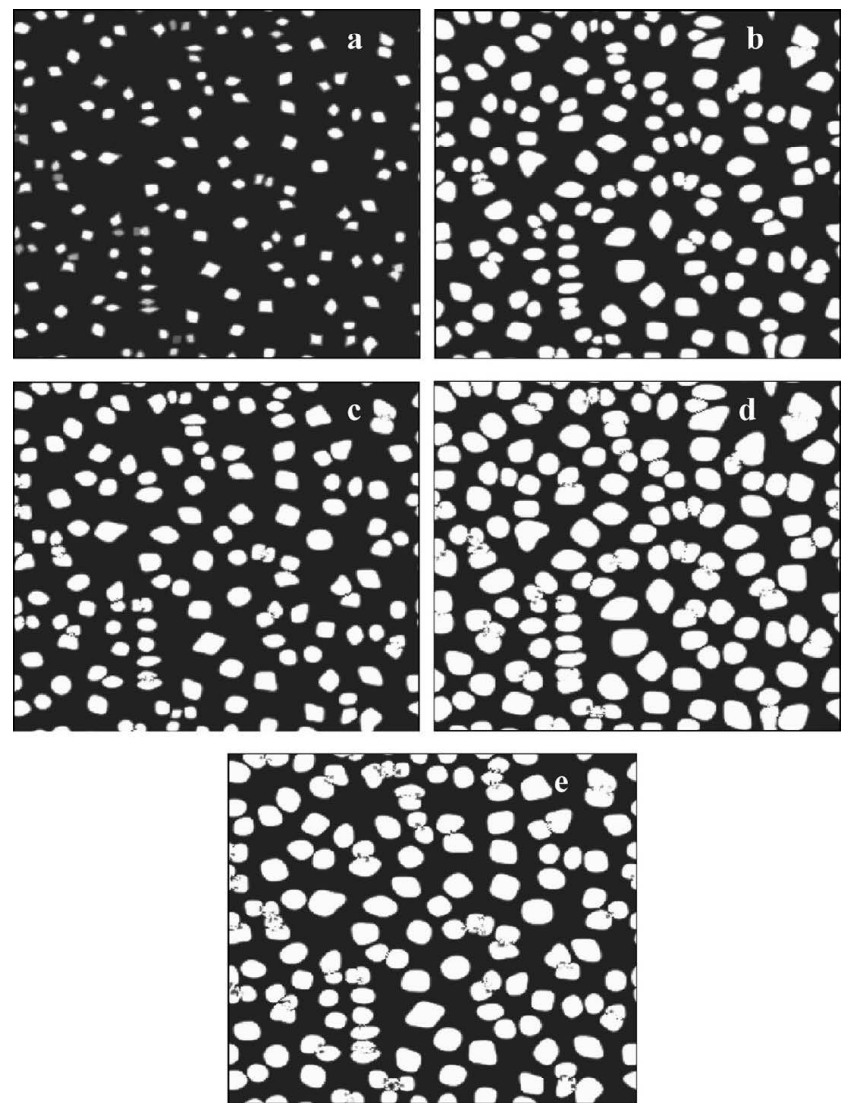

Fig. 7. Simulated micrographs of the grain refined melt (cooling rate $9.5 \mathrm{~K} / \mathrm{s}$ ) after (a) 2, (b) 3, (c) 4, (d) 5 and (e) 6 seconds. highest solid fraction within the bulk melt is observed in case of $11 \mathrm{~K} / \mathrm{s}$ cooling rate $(0.36)$ and lowest in case of 8.3 $\mathrm{K} / \mathrm{s}$ cooling rate $(0.21)$ after 6 seconds. This is attributed to the lowest melt temperature in case of $11 \mathrm{~K} / \mathrm{s}$ cooling rate

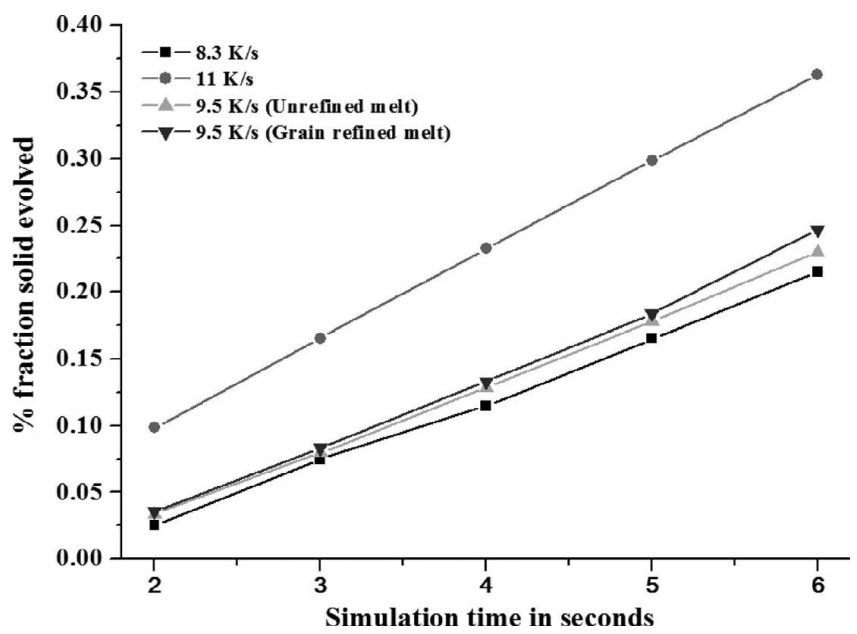

Fig. 9. Solid fraction evolved within the bulk liquid.

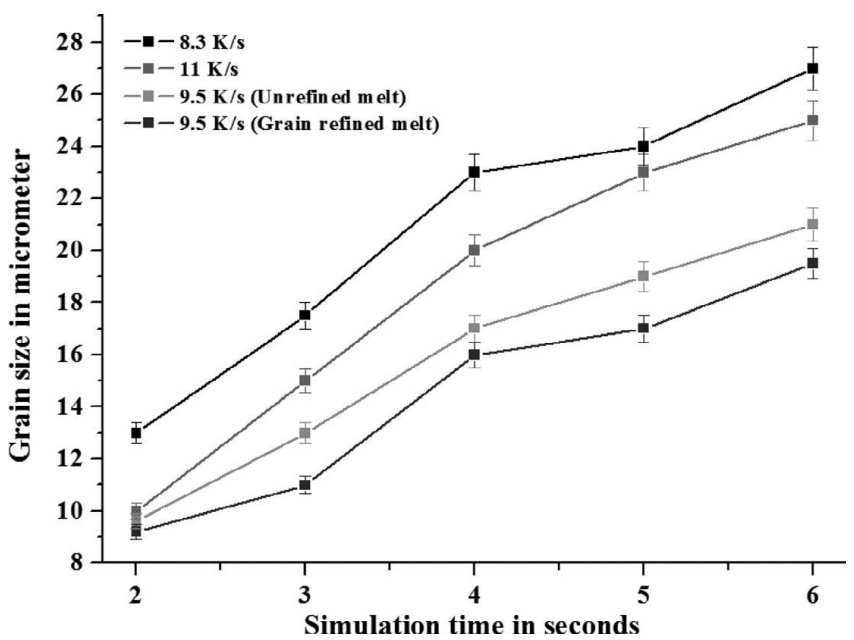

Fig. 10. Grain size of the primary particles present within the simulation domain.

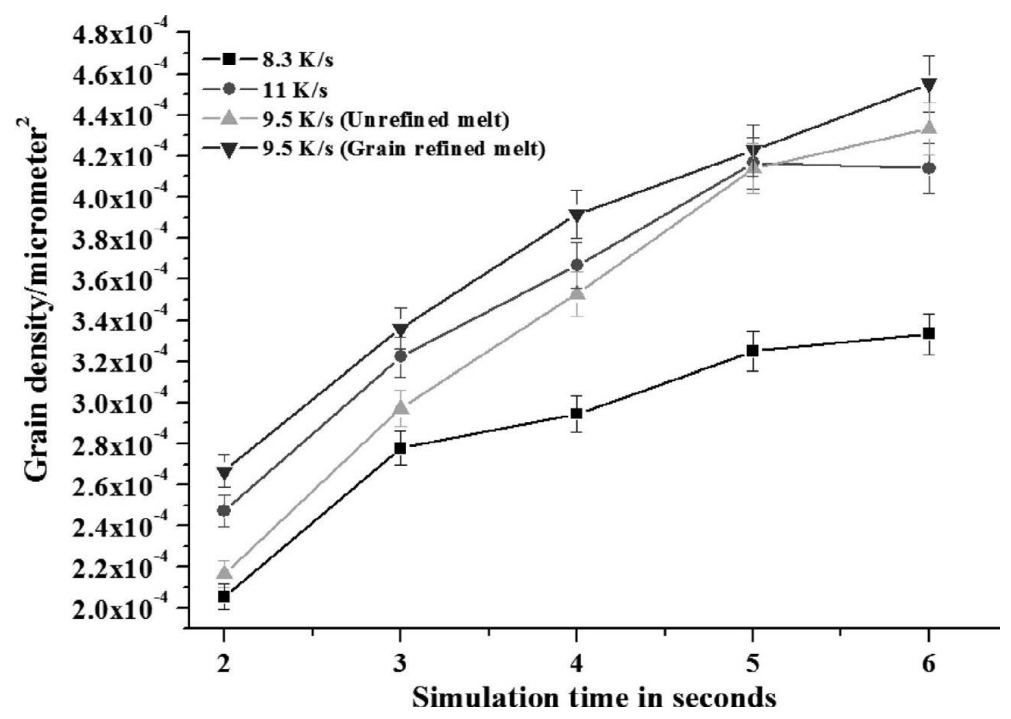

Fig. 8. Grain density present within the simulation domain for different simulation conditions. 


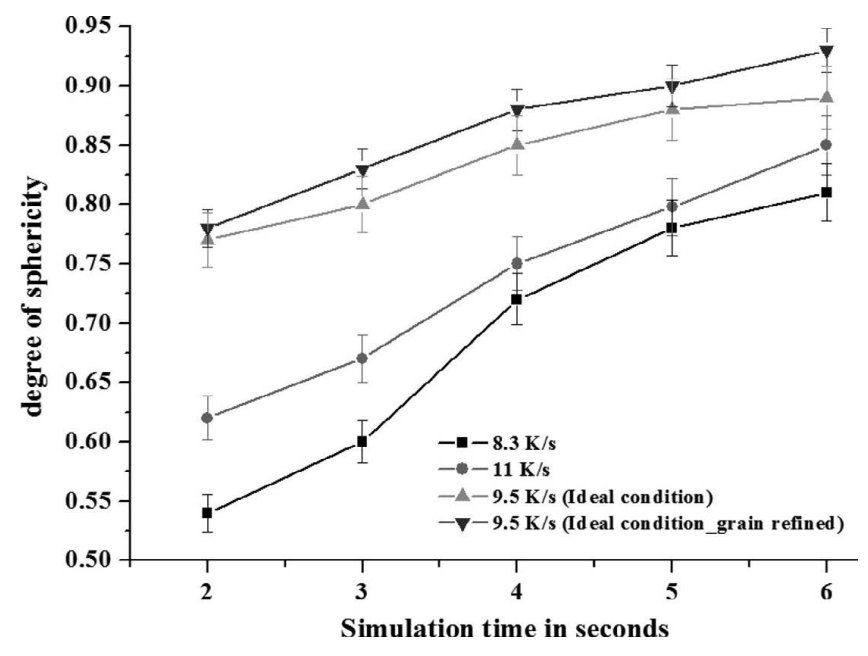

Fig. 11. Sphericity of the primary Al phase for different simulation conditions.

(after 6 seconds) compared to any other condition studied in this work, which is due to the higher rate of heat removal in this case. Figure 10 shows the grain size of primary particles present within the simulation domain. Higher cooling rate is found to have diminishing returns with regard to grain size of primary particles due to coagulation and particle sintering effects. A minimum grain size of $19.5 \mu \mathrm{m}$ is achieved in case of grain refined melt due to the presence more nuclei at the initial stage of solidification compared to any other case studied here. Sphericity of primary Al phase for the conditions studied in this work is reported in Fig. 11. Grains having highest sphericity are observed in case of grain refined melt due to the presence of more nuclei which facilitates spherical growth. Several researchers have confirmed the phenomena of achieving spherical growth when higher nuclei density is present within the melt. ${ }^{11)}$ It is interesting to note that though higher grain density is present at $11 \mathrm{~K} / \mathrm{s}$ cooling rate upto 5 seconds compared to that of $9.5 \mathrm{~K} / \mathrm{s}$ cooling rate, the degree of sphericity of primary particles are still higher in the latter case throughout the whole simulation period. The reason behind this phenomenon is high curvature and edgy appearance of the primary Al grains at higher cooling rate, which orients primary particles towards dendritic growth if further cooling is provided. Maximum sphericity value obtained in case of grain refined melt at the end simulation is 0.93 , which is excellent in terms of semi-solid slurry quality for further processing into shapes.

\subsection{Experimental Results}

\subsubsection{Temperature Measurements}

Figure 12 shows the temperature vs. flow time plots obtained from thermocouples placed along the melt flow direction of the cooling slope in case of grain refined alloy. Temperature measurements are performed at middle and exit sections of the slope to estimate evolving solid fraction within the solidifying melt during its flow along the cooling slope. Faster temperature drop is observed in case of grain refined melt (Fig. 12) compared to that of unrefined one (Fig. 3) due to less melt velocity. Grain refiner addition into the melt aids in decreasing the slurry velocity during its flow along the cooling slope due to the presence of more primary Al phase, which increases slurry viscosity. Higher latent heat release due to nucleation of more primary aluminum particles and enhanced cooling time due to less slurry velocity in case of grain refined melt is found to be responsible for less slope exit temperature of the slurry in this case (840 K), compared to that of unrefined case (846 K). Solid

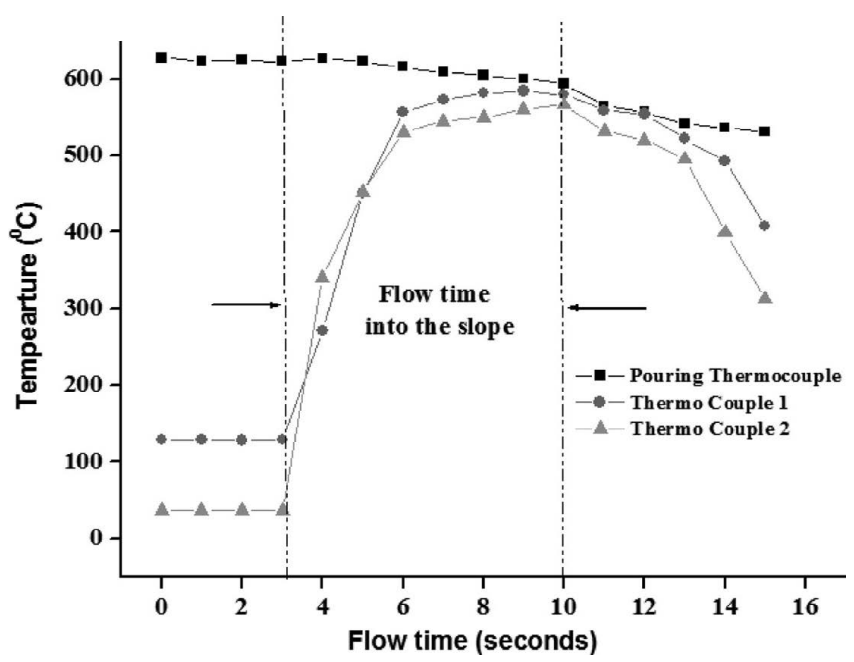

Fig. 12. Temperature vs. flow time plot for the grain refined alloy.

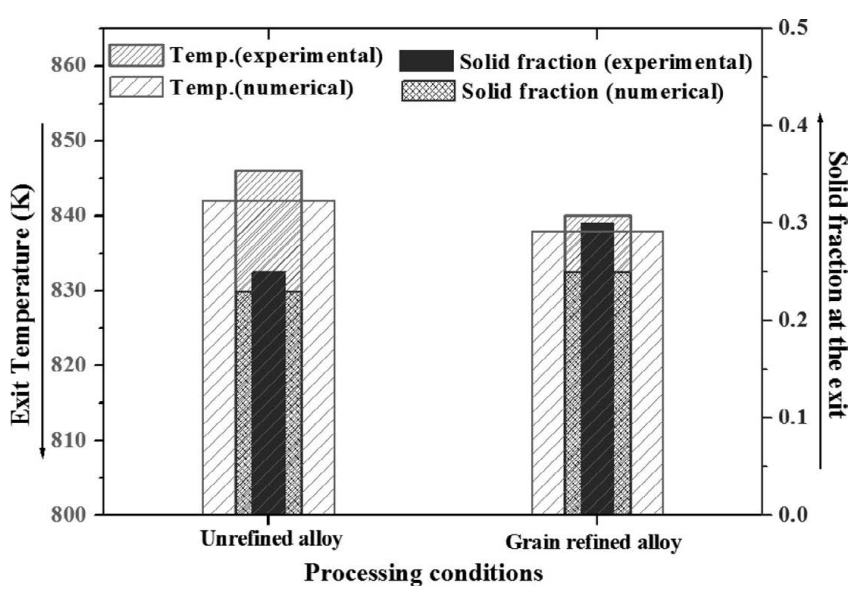

Fig. 13. Comparison of experimental and numericalfindings.

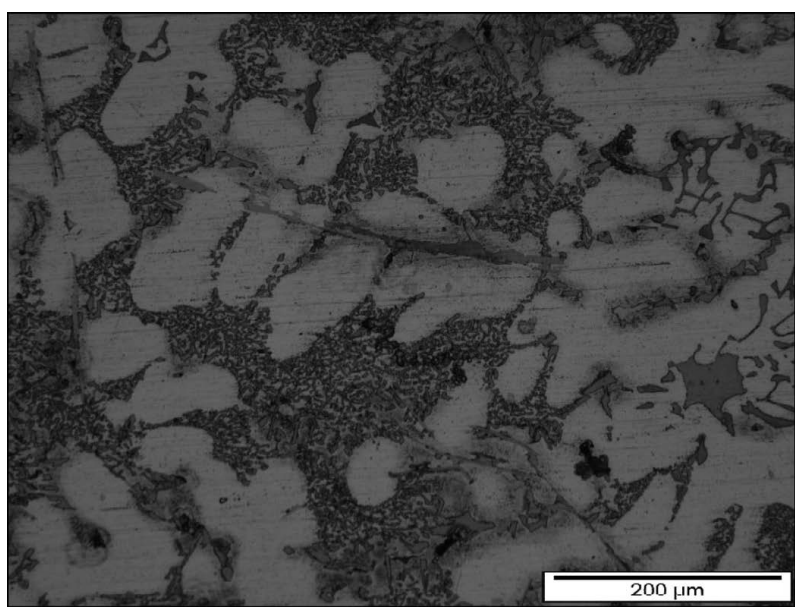

Fig. 14. Microstructure of as received A380 Al alloy.

fraction present within the slurry while exiting cooling slope is estimated by performing Scheil calculations. ${ }^{22,23)}$ Comparison of numerical findings and experimentally found slurry temperature and solid fraction present in it at slope exit is shown in Fig. 13. Results confirm reasonable accuracy of the phase field simulation results.

\subsubsection{Microstructural Characterization}

Dendritic microstructure is observed in case of as-received 
A380 alloy sample (Fig. 14). On the other hand, mixture of spheroids and equiaxed primary Al grains are observed in the oil quenched slurry samples, collected from start, middle and exit sections of the melt flow (approximately after 4, 5 and
6 seconds of melt flow initiation). The mechanism of near spherical microstructure formation during cooling slope processing of the alloy is described as follows:

The superheated melt is poured into the cooling slope at
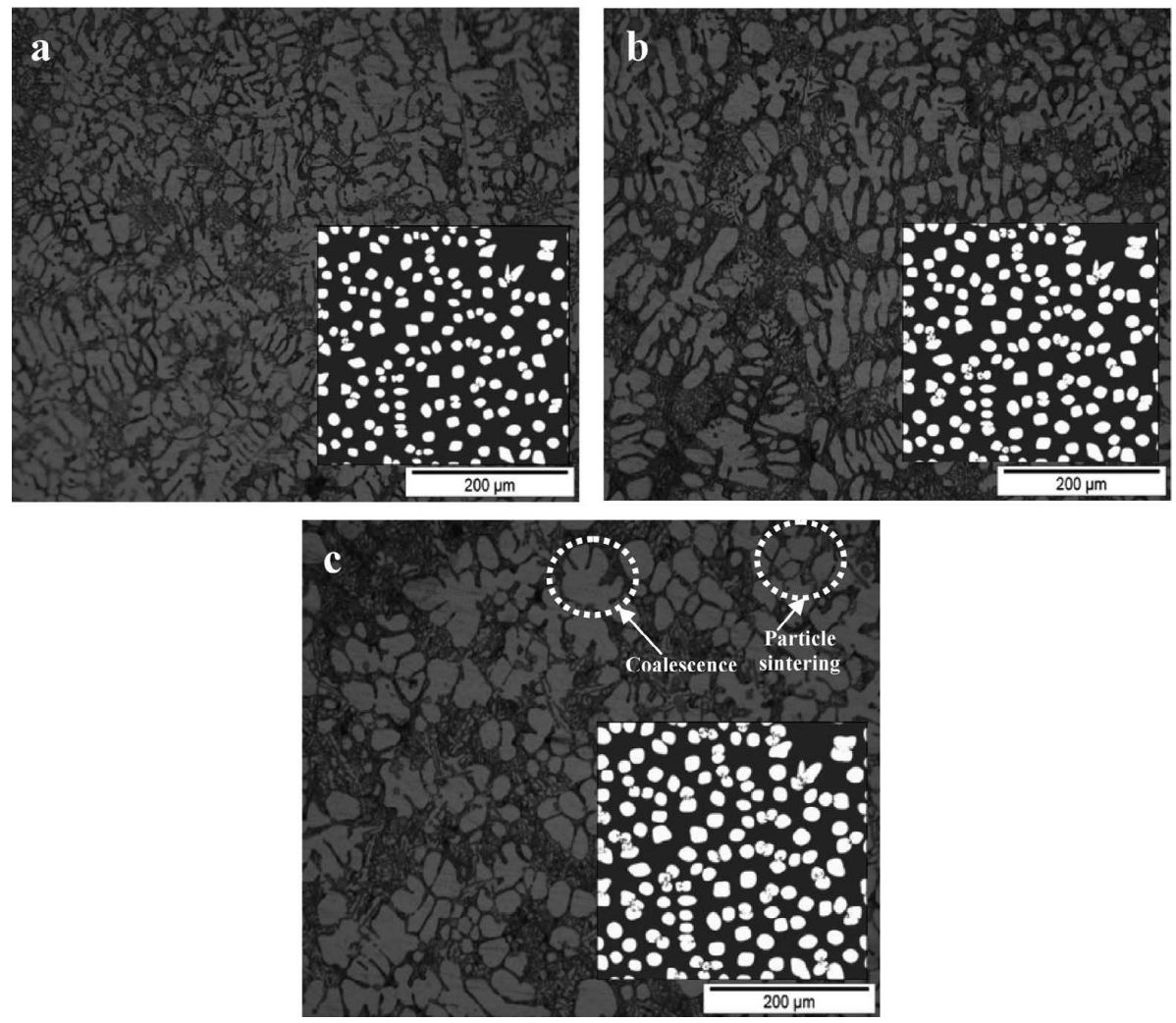

Fig. 15. Optical micrographs and subsequent simulated micrographs of the evolution samples of untreated alloy: (a) Start, (b) Middle and (C) Exit.
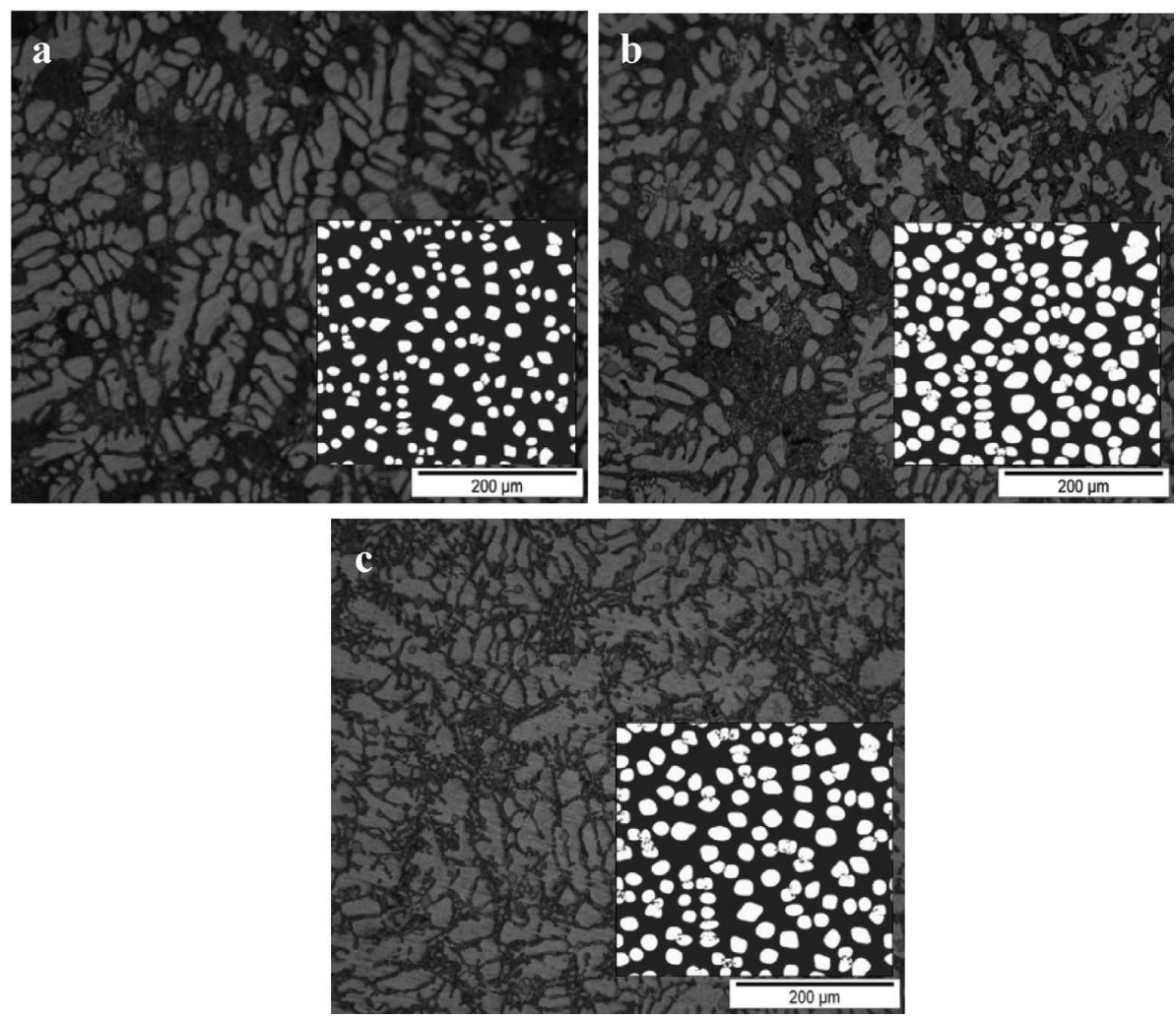

Fig. 16. Optical micrographs and subsequent simulated micrographs of the evolution samples of grain refined alloy: (a) Start, (b) Middle and (C) Exit. 
$903 \mathrm{~K}$ and then it continues to solidify while undergoing shear driven flow along the slope. Initially, the primary solid particles nucleate and grow on the slope wall and then get detached from there because of shearing action of the melt flow. The flowing melt carries the detached crystals forward in the flow direction i.e., towards the slope exit. Coalescence and ripening acts as the principal growth mechanism of the particles originated from heterogeneous nucleation ${ }^{42}$ and fragmentation in the slope wall. Instant heat extraction from the melt while it comes in contact with the slope surface leads to generation of more nucleation sites which causes successive formation of more nuclei, which, in turn, facilitates generation of more equiaxed and near spherical grains within the slurry.

Optical micrograph of the sample, collected from the start position of melt flow (Fig. 15(a)) shows mixture of equiaxed grains and finer dendrites. As melt progresses towards the middle position, the microstructure reveals growth in terms of enhanced size of the grains due to coalescence of dendritic arms and ripening of equiaxed grains (Fig. 15(b)). Coalescence leads to increase mean free path of diffusion in solid phase ${ }^{43)}$ which helps the grains to attain spherical shape. At the exit section, the grains attain nearly globular morphology, as evident from the optical micrograph of Fig. 15(c). Figure 16 shows optical micrographs of the grain refined slurry samples. As explained earlier, grain refiner facilitates nucleation of higher amount of primary phase and orients them towards spherical growth. ${ }^{44,45)}$ Melt samples

a

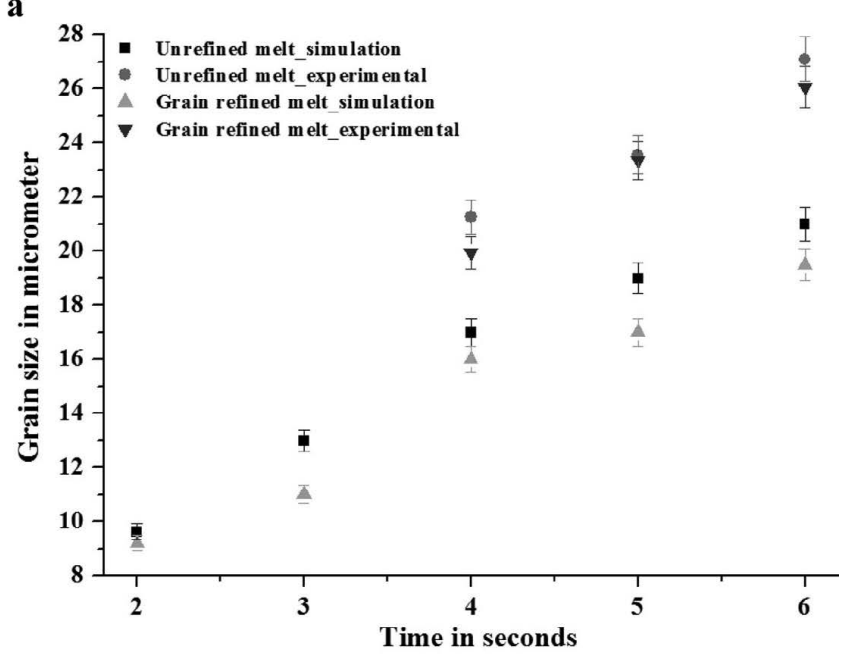

b

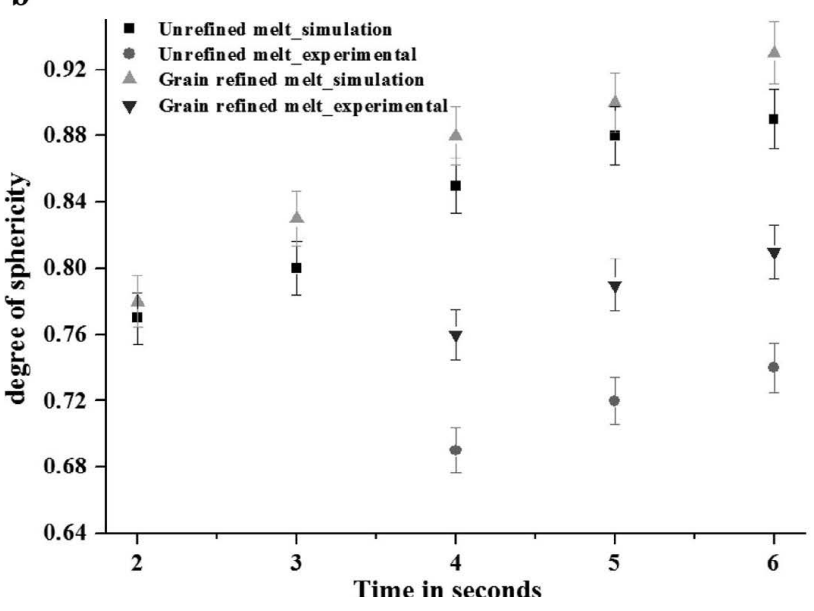

Fig. 17. Comparative (a) grain diameter and (b) sphericity values of primary $\mathrm{Al}$ phase observed in the simulated and experimental micrographs. collected from the start position of the slope show rosettelike primary $\alpha$ phase (Fig. 16(a)), while those collected from the middle section reveal a mixture of spheroids and equiaxed grains (Figs. 16(b) and 16(c)). The eutectic fraction is found to be maximum at the start, and it decreases while melt flows down the slope. Increasing eutectic fraction is due to the rejection of solutes during ripening and coalescence driven growth of primary $\alpha$-Al phase. Eutectic fraction is even lower in case of gain refiner added samples as it favours growth of $\alpha$-Al more by limiting eutectic phase growth. Comparison with the simulated micrographs is also shown in Figs. 15 and 16. Differences observed between simulated and experimental micrographs are due to the assumptions considered in the present phase field model such as $2 \mathrm{D}$ simulation domain, simplified temperature evolution model, seed density model of solid nucleation, simplified composition of the alloy (omitting alloy elements having presence lower than $2 \%$ ), and not considering convection.

Figure 17 shows the comparative grain diameter and sphericity values of the primary Al phase observed in the simulated and experimental micrographs. Error bars of $\pm 3 \%$ are considered to take care of errors associated with manual intervention to calculate the grain size and sphericity values. Grain size is higher and sphericity is lower in case of experimental results and also in contrast of simulation results, presences of some finer dendrites have been observed in the experimental micrographs. This difference is attributed to the presence of melt convection, crystal fragmentation and shear driven spherodisation of the primary Al particles during experiments.

\section{Summary and Conclusion}

Phase field simulation is identified as an effective tool to understand the physics associated with near spherical and equiaxed microstructure formation of A380 Al alloy during cooling slope slurry generation process. Based on the findings of initial experimentation and subsequent evaluation of microstructural morphology, seed density nucleation model is utilized to simulate microstructure evolution following the phase field methodology. Studies on the effect of cooling rate suggest that exists an optimum cooling rate for producing the best semisolid slurry. Excess cooling rate tends to reduce sphericity of the primary aluminum grains, and produces an edgy appearance of primary $\mathrm{Al}$ grains, which triggers dendritic growth, while a low cooling rate results in decreased solid fraction, grain density and ripening driven growth of the primary particles which degrades their degree of sphericity. It is also observed that use of grain refiner in the melt results in enhanced nucleation of primary phase from the bulk melt which facilitates the spheroidal growth of grains. Experiments performed in this study with the refined and unrefined melt shows reasonable agreement of the phase field simulation results with the experimental findings.

Numerical finding slightly under predicts the melt temperature and solid fraction, which can be attributed to some of the assumptions made in the model. Although the current model needs further improvement such as improved nucleation model based on undercooling, consideration of grain coagulation etc., still it is capable of predicting the trend correctly and providing insight into the microstructure evolution mechanism during cooling slope slurry generation process. The present model is also capable of predicting microstructural features in different process conditions, what can be utilized to establish process control. The phase field model is also found to be a valuable tool to predict the primary particle size and its sphericity, which serve as the parameters to determine the quality of the semi-solid slurry. 


\section{Acknowledgement}

Authors would like to thank DST, New Delhi and CSIR, New Delhi for their financial support to this work.

\section{REFERENCES}

1) W. J. Boettinger, S. R. Coriell, A. L. Greer, A. Karma, W. Kurz, M. Rappaz and R. Trivedi: Acta Mater., 48 (2000), 43.

2) L. Q. Chen: Annu. Rev. Mater. Res., 32 (2002), 113.

3) M. Militzer: Curr. Opin. Solid State Mater. Sci., 15 (2011), No. 3 , 106.

4) N. Moelans, B. Blanpain and P. Wollants: Calphad, 32 (2008), 268.

5) I. S. Loginova and H. M. Singer: Rep. Prog. Phys., 71 (2008), 1.

6) I. Steinbach: Model. Simul. Mater. Sci. Eng., 17 (2009), 1.

7) L. Granasy, T. Pusztai and J. A.Warren: J. Phys.: Condens. Matter, 16 (2004), R1205.

8) W. J. Boettinger, J. A. Warren, C. Beckermann and A. Karma: Annu. Rev. Mater. Res., 32 (2002), 163.

9) H. V. Atkinson: Prog. Mater. Sci, 50 (2005), 341.

10) Z. Fan: Int. Mater. Rev., 47 (2002), 49.

11) R. Canyook, J. Wannasin, S. Wisuthmethangkul and M. C. Flemings: Acta Mater., 60 (2012), 3501.

12) T. Haga: J. Mater. Process. Technol., 130-131 (2002), 558.

13) Y. Birol: J. Mater. Process. Technol., 207 (2008), 200.

14) Z. L. Ning, H. Wang and J. F. Sun: Mater. Manuf. Process., 25 (2010), No. 7, 648

15) E. A. Vieira, A. M. Kliauga and M. Ferrante: Scr. Mater., 57 (2007), 1165 .

16) S. Gencalp and N. Saklakoglu: Mater. Manuf. Process., 25 (2010), 943.

17) S. Gowri and F. H. Samuel: Metall. Mater. Trans. A, 25A (1994), 437.

18) S. Farahany and A. Ourdjini: Mater. Manuf. Process., 28 (2013), No. $6,657$.

19) S. H. Avner: Introduction to Physical Metallurgy, 2nd ed., Tata McGraw-Hill Education, India, (2012), 481

20) N. S. Abtan and K. H. Ghlaim: Iraqi J. Mech. Mater. Eng., 12 (2012), No. 2, 334

21) H. Guo, X. Yang, B. Hu and G. Zhu: J. Wuhan Univ. Technol.-Mater. Sci. Ed., 22 (2007), 590.

22) P. Das, S. K. Samanta, H. Chattopadhyay and P. Dutta: Acta Metall. Sin. (English Letters), 25 (2012), No. 5, 329.

23) P. Das, S. K. Samanta, H. Chattopadhyay, B. B. Sharma and P. Dutta: Mater. Sci. Technol., 29 (2013), No. 1, 83.
24) P. Das, S. K. Samanta, H. Chattopadhyay and P. Dutta: Solid State Phenomena, 192-193 (2013), 341.

25) G. Lasko, M. Apel, A. Carre, U. Weber and S. Schmauder: Adv. Eng. Mater., 13 (2012), 1.

26) M. G. Mecozzi, J. Eiken, M. Apel and J. Sietsma: Comput. Mater. Sci., 50 (2011), 1846.

27) Y. Nomura, S. Minamoto and S. Nomoto: ISIJ Int., 50 (2010), No. $12,1920$.

28) M. Bunck, N. Warnken and A. B. Polaczek: J. Mater. Process. Technol., 210 (2010), 624.

29) G. Zimmermann, L. Sturz, M. Walterfang and J. Dagner: Int. J. Cast Met. Res., 22 (2009), No. 1-4, 335.

30) I. Steinbach: Acta Mater., 57 (2009), 2640.

31) S. Nomoto, S. Minamoto and K. Nakajima: ISIJ Int., 49 (2009), No. 7, 1019 .

32) B. Bottger, A. Carre, J. Eiken, G. J. Schmitz and M. Apel: Trans. Indian Inst. Met., 62 (2009), No. 4-5, 299.

33) B. Bottger, J. Eiken and M. Apel: J. Comput. Phys., 228 (2009), 6784.

34) B. Bottger, J. Eiken and I. Steinbach: Acta Mater., 54 (2006), 2697.

35) I. Steinbach, B. Bottger, J. Eiken, N. Warnken and S. G. Fries: $J$. Phase Equilib. Diff., 28 (2007), No. 1.

36) J. Eiken, B. Bottger and I. Steinbach: Phys. Rev. E, 73 (2006), 066122.

37) Tatsoft, SCADA Data Acquisition Software, The Proud Company Bridgeville, PA, http://www.proudco.com/tatsoft-scada-softwarepittsburgh-pa/, (accessed 2013-12-18).

38) P. Das, S. K. Samanta, H. Chattopadhyay, P. Dutta and B. R. K. Venkatapathi: Trans. Indian Inst. Met., 65 (2012), No. 6, 669.

39) P. Das, S. K. Samanta, T. Ray and B. R. K. Venkatapathi: Adv. Mater. Res., 585 (2012), 354.

40) P. Das, S. Dutta and S. K. Samanta: Proc. Inst. Mech. Eng. Part B: J. Eng. Manuf., (2013), DOI: 10.1177/0954405413490162.

41) Micress User Guide, version 6.1, Vol. 2 (running micress), ACCESS Materials \& Processes, Aachen, Germany, http://www.micress.de, (accessed 2013-07-25).

42) R. Canyook, S. Petsut, S. Wisutmethangoon, M. C. Flemings and J. Wannasin: Trans. Nonferrous Met. Soc. China, 20 (2010), 1649.

43) H. M. Guo, X. Q. Luo, A. S. Zhang and X. J. Yang: Trans. Nonferr. Met. Soc. China, 20 (2010), 1361.

44) K. T. Kashyap and T. Chandrasekhar: Bull. Mater. Sci., 24 (2001), 345 .

45) Z. Liu, W. M. Mao and Z. D. Zhao: Acta Metall. Sin. (English Letters), 21 (2008), 57. 